\title{
APLICAÇÃO DE REDES BAYESIANAS PARA ANÁLISE DE PROGRAMAS SÓCIO TORCEDOR
}

APPLICATION OF THE BAYESIAN NETWORKS FOR ANALYSIS OF FANS MEMBERSHIP PROGRAMS

Recebido em 20.12.2018. Aprovado em 28.05.2019

Avaliado pelo sistema double blind review

DOI: https://doi.org/10.12712/rpca.v13i2.27526

\section{Pâmela de Souza Dias}

pandjoca@yahoo.com.br

FEA-RP - Departamento de Administração de Organizações / Universidade de São Paulo (USP) - Ribeirão

Preto/São Paulo, Brasil

ORCID: https://orcid.org/0000-0002-5849-3886

\section{Plínio Rafael Reis Monteiro}

preisufmg@gmail.com

FACE - Departamento de Administração de Empresas/Universidade Federal de Minas Gerais (UFMG) - Belo

Horizonte/Minas Gerais, Brasil

ORCID: https://orcid.org/0000-0002-5626-2945

\section{Evandro Marcos Saidel Ribeiro}

\section{esaidel@usp.br}

FEA-RP - Departamento de Administração de Organizações/ Universidade de São Paulo (USP) - Ribeirão

Preto/São Paulo, Brasil

ORCID: https://orcid.org/0000-0001-7213-0240

\section{Resumo}

O marketing esportivo trata da comercialização da imagem através do esporte e representa uma opção eficiente de aproximação com o público. Nesse contexto, o Programa Sócio Torcedor (PST) tem um potencial significativo para o Brasil. O artigo objetiva identificar a estrutura de valor percebido por distintas características sociodemográficas em um conjunto de atributos oferecidos pelos PSTs e propor um modelo elaborado com Rede Bayesiana (RB) que identifique o plano ideal para públicos distintos. Os dados foram coletados através de um survey online com população composta por torcedores dos times selecionados. Foram analisados com Análise Conjunta (AC) e RB. Verificou-se que o desconto nos ingressos e os preços são os atributos de maior valor para os torcedores. O trabalho contribuiu com a proposta de um instrumento capaz de descrever a percepção de valor nos PSTs e o modelo proposto com a RB mostrou-se uma ferramenta adequada para complementar a AC.

Palavras-chave: Redes bayesianas. Programas de fidelidade. Marketing esportivo. Valor percebido.

\begin{abstract}
Sports marketing deals with image commercialization through the sport and represents an efficient option of approaching with the public. In this context, the Socio Fans Program (SFP) has a significant potential for Brazil. The article aims to identify the structure of value perceived by different sociodemographic characteristics in a set of attributes offered by the PSTs and proposes a model elaborated with the Bayesian network (BN) that identifies the ideal plan for different publics. The data was collected through an online survey with the population was made up of fans from the selected teams. Were analyzed with Conjoint Analysis (CA) and BN. It was verified that the discount on tickets and the price of the SPFs are the attributes of greater value to the fans. The paper contributed as a proposal of an instrument capable of describing the perception of value in the SPFs and the model with the BN showed to be an adequate tool to complement the CA.
\end{abstract}

Keywords: Bayesian networks. Loyalty program. Sports marketing. Perceived value. 


\section{Introdução}

Desde os primórdios do futebol no Brasil a modalidade adquiriu várias peculiaridades, passando pela transformação de um esporte elitizado para um fenômeno popular. Tornou-se uma manifestação presente no cotidiano dos brasileiros, abrangendo relações sociais e econômicas (MARTINS, 2016). Portanto, é um esporte com ampla participação popular e uma atividade cujo público demonstra um apego significativo por seus times (SCHARF et al., 2016).

Toda essa popularidade que envolve o esporte, resultou em milhões de jogadores e atraiu bilhões de torcedores. Diante disso, se tornou um grande negócio em que as equipes profissionais geram enormes receitas (MÜLLER; SIMONS; WEINMANN, 2017).

Portanto, os clubes estão compreendendo a necessidade de inserir instrumentos do marketing em sua gestão, tanto a nível local como internacional, analisando os potenciais interessados em seus times e selecionando os considerados mais lucrativos (financeiramente ou de outra forma) (VRONTIS, et al., 2014).

Iniciativas de profissionalização da administração e o alinhamento dos diferentes stakeholders, buscando alcançar as melhores práticas para o time e sua sustentabilidade em longo prazo, são medidas que fortalecem esse novo modelo. A adoção desse tipo de estratégia pode constituir-se em um diferencial na busca por recursos ao estimular uma melhor estruturação dos clubes (MARQUES; COSTA, 2016).

O nível de envolvimento dos torcedores com seus clubes é um diferencial para ações de marketing mais eficazes ao se comparar com segmentos convencionais. Isso ocorre em razão do mercado futebolístico possuir a lealdade ao time como fator de barreira de entrada para a concorrência, uma vez que um torcedor não está disposto a consumir ofertas de outros clubes (FLEURY et al., 2016). Nesse sentido, a oportunidade para criar retorno em investimentos em ações de marketing nos clubes pode ser considerada privilegiada.

Os Programas Sócios Torcedores (PSTs) se destacam nessa direção, pois são uma alternativa para aumentar a receita e viabilizar um projeto de modernização dos clubes brasileiros. Ademais, tais programas atuam como mecanismo de conquista do torcedor, permitindo um melhor entendimento de seu público de como conquistá-lo e mantê-lo como parceiro. Os PSTs tratam de uma prática de marketing que permite estreitar o relacionamento do clube com o torcedor (MARTINS, 2016). O Sport Club Internacional foi o primeiro clube brasileiro a conceber e executar filosofias que colocam o torcedor como foco do negócio, sendo pioneiro na criação do PST no Brasil, iniciado no ano de 2002 (AVANCINI et al., 2010).

Em estudos de marketing, emprega-se o conceito de valor percebido como ponto de partida na construção de novas propostas de valor. O contexto do futebol tem uma significativa variedade de público, portanto, em termos mercadológicos, é necessário mapear as distintas percepções de valor dessas pessoas. Pode-se entender o valor percebido como a contraposição dos sacrifícios feitos pelos consumidores com os benefícios da oferta. Entende-se por sacrifício todos os esforços e custos enfrentados durante o processo de avaliação das opções, escolha e utilização de um bem ou serviço pelo consumidor. Já os benefícios são os resultados ou soluções de problemas na perspectiva do consumidor (RAVALD; GRÖNROOS, 1996). Logo, compreender e quantificar o valor percebido influencia a aceitação da oferta de modo que sua análise é uma etapa que deve preceder a definição de uma estratégia de um PST.

Com base nas informações expostas, o presente artigo pretendeu responder o seguinte problema de pesquisa: 
Qual é a percepção de valor, quanto aos atributos e benefícios dos Programas Sócios Torcedores dos times classificados na série A do Campeonato Brasileiro de Futebol de 2016, para diferentes torcedores com características sociodemográficas distintas?

O objetivo principal foi identificar a estrutura de valor percebido por distintas características sociodemográficas em um conjunto de atributos oferecidos pelos PSTs e a partir dos resultados propor um modelo elaborado com rede bayesiana que identifique o plano ideal para públicos distintos.

Além dessa seção introdutória, o artigo está organizado da seguinte forma: a próxima seção apresentará a fundamentação teórica, a terceira seção descreve os procedimentos metodológicos e em seguida é apresentada a análise dos resultados. A última seção relata as conclusões desse estudo, assim como as limitações e sugestões para pesquisas futuras.

\section{Marketing esportivo}

Existem muitas organizações esportivas, especialmente as pequenas, que atribuem a responsabilidade do marketing a um funcionário que não tem experiência no campo do marketing esportivo. Porém, tal atitude pode ser prejudicial para os objetivos dos times, principalmente no desenvolvimento e implementação de um plano de marketing esportivo, o qual pode ser complicado. (DICKLER, 2015).

A expressão marketing esportivo está relacionada ao marketing da imagem de um bem ou serviço por meio do esporte. Refere-se as organizações que utilizam o esporte para identificar, propor, e comunicar propostas de valor que satisfaçam os diversos stakeholders do meio esportivo, tais como torcedores, patrocinadores, ou gestores de times (POZZI, 1998.

A relação do marketing com futebol se iniciou após a Segunda Guerra Mundial, momento em que estudiosos despertaram o interesse na visibilidade desse espetáculo e na possibilidade de expor marcas e ofertas associadas aos times (MARTINS et al. 2015). Nesse sentido, os torcedores tornaram-se os atores principais do mercado futebolístico. Isso reforça a importância de estudar seus diferentes tipos, assim como a necessidade de os clubes estabelecerem relações recíprocas com os torcedores, a fim de aumentar seus níveis de internalização de marca (time) e contribuir para o aumento das intenções comportamentais positivas. Por exemplo, exibir fotos de sócio torcedores no site do clube ou oferecer ingressos gratuitos para trazerem amigos aos jogos, são estratégias que podem criar um nível mais alto de congruência de valor entre o torcedor e a equipe (BISCAIA et al., 2016).

O aumento da importância do Brasil na indústria do esporte, principalmente por sediar recentemente dois dos principais eventos esportivos mundiais, a Copa do Mundo de Futebol (2014) e os Jogos Olímpicos (2016), pode ser um fator significativo para o crescimento de publicações na área do marketing esportivo. Apesar da quantidade da produção acadêmica nacional na área ainda ser pequena, nota-se um crescimento no número de estudos publicados (FAGUNDES et al., 2012).

Seja no papel de simpatizante, torcedor e também como praticante de uma modalidade, o torcedor é um público notavelmente fiel ao seu esporte favorito, sendo essa uma vantagem a se explorar no campo do marketing esportivo. O envolvimento dos torcedores propicia, dessa forma, o desenvolvimento de um marketing de relacionamento e com a possibilidade de um torná-lo duradouro (LOIS, 2013).

\section{Valor Percebido}

Considera-se como o valor percebido pelo consumidor, a avaliação geral referente ao que é recebido (benefícios) em relação ao que é dado (sacrifício) durante a aquisição de alguma oferta. Tal julgamento é feito com base na combinação de qualidade do produto, do serviço prestado, preço justo e a experiência de compra como um todo. O valor percebido está presente na busca para satisfazer necessidades e gerar a satisfação. O processo de decisão de compra ocorre com a percepção do valor dos itens disponíveis e é central para a tomada de decisão do usuário. Desta forma, compreender os fatores que envolvem o 
valor torna-se essencial para que os gestores consigam entregar uma proposta valiosa aos seus consumidores (CHANG; DIBB, 2012).

Porém, é possível interpretar o que motiva as escolhas específicas dos usuários a partir de perspectivas específicas de valor. Quando se trata do valor funcional, o consumidor avalia à capacidade utilitária ou física da oferta adquirida. Já para o valor social, associa um ou mais aspectos, positivos ou negativos, de grupos sociais do contexto desse consumidor. Semelhante a esse raciocino, o valor emocional trata-se da capacidade de uma oferta despertar sentimentos ou estados afetivos no usuário. O valor epistêmico, geralmente, envolve uma curiosidade ou novidade. Por último, o valor condicional resulta de uma situação específica ou um conjunto de circunstâncias que motivam uma escolha. A decisão de consumo pode ser influenciada por qualquer um dos cinco valores, por uma combinação de alguns deles ou pelos cinco em conjunto (SHETH; NEWMAN; GROSS, 1991).

No contexto do futebol, considerando clubes como produtos, nota-se uma variedade de mercados-alvos. O valor percebido pelos torcedores pode ser considerado intangível e os parceiros, de diferentes segmentos, consideram valores diferentes. Essas características permitem aos gestores dos clubes projetarem suas proposições de valor e capitalizar os atributos abrangentes de seus times, tanto individual como coletivamente, posicionando seu valor de acordo com as imagens e associações que desejam. Portanto, em relação ao futebol a definição de valor precisa ir além da conceitual, abrangendo a identificação com os mercados-alvo e torcedores (VRONTIS, et al., 2014).

Nesse sentido, os clubes devem destacar aspectos do sucesso em campo, o comprometimento e competência da gestão, as tradições duradouras do clube e as características do estádio da casa, a fim de gerenciar adequadamente a marca do time, atraindo torcedores e stakeholders (BISCAIA et al., 2016).

Logo, os gestores e profissionais de marketing devem ter uma profunda compreensão do significado do conceito de valor percebido pelo consumidor para estarem aptos a satisfazê-los. Uma proposta de valor atua como um diferencial para as organizações alcançarem um desempenho satisfatório. Neste contexto, a segmentação de mercado também se torna importante, pois direciona a empresa ao seu público-alvo. Além disso, é vantajoso escolher e manter as parcerias certas, elaborando assim uma proposta de valor única e difícil de ser copiada (SOUZA; BATISTA, 2017).

\section{Programa Sócio Torcedor}

Os programas de fidelização sugiram a partir de companhias aéreas que buscavam uma forma de retribuir a preferência dos seus consumidores e também tinham o objetivo de estabelecer um vínculo com seus usuários. Esperava-se assim, que os consumidores adotassem um relacionamento de médio e longo prazo com a organização. Logo a iniciativa expandiu para demais setores de prestação de serviços e financeiros (ROCHA; TOLEDO; ALMEIDA, 2008). Tal percepção também é reconhecida entre os times brasileiros de futebol, os quais perceberam que um maior engajamento de seus torcedores pode trazer um aumento nas receitas (CHAVES; GOSLING; MEDEIROS, 2014), em especial, com os Programas Sócio Torcedor.

Os programas de fidelidade são encontrados em diversos formatos, porém, o sistema de acúmulo de pontos e níveis de classificação do consumidor são os mais comuns. No primeiro caso, conforme ocorre o consumo também há computação de pontos, os quais poderão ser revertidos em prêmios. Já no segundo modelo, a medida que se torna frequente a recompra ou o valor adquirido pelo cliente, o consumidor é classificado em um nível especial (exemplo, cliente VIP) e recebe benefícios por essa condição (SEPTIANTO; AN; CHIEW; PARAMITA; TANUDHARMA, 2019). Os PSTs utilizam ambas estratégias.

Pode-se apontar que o Programa Sócio Torcedor é um modelo inovador de fidelização que obteve sucesso nos principais clubes europeus, o que estimulou os clubes brasileiros a implementarem a 
abordagem. O programa tem um grande potencial a ser explorado pelos clubes nacionais, possibilitando que o faturamento dos clubes seja menos dependente dos resultados em campo e com oscilações menores que as receitas resultantes de bilheteria (CARDOSO; SILVEIRA, 2014).

Ao aderir a um PST, o torcedor se compromete a pagar uma mensalidade em troca de benefícios, como a possibilidade de comprar ingressos antecipadamente e, dependendo do plano, com desconto. Nesse sentido, o desconto oferecido ao sócio é um valor referente à antecipação da receita com bilheteria. Em jogos de pouca presença de torcedores, parte da receita dos ingressos já estará garantida com o pagamento das mensalidades dos sócios. Portanto, caracteriza-se como um investimento relevante para os clubes, estreitando, desta maneira, o relacionamento com o torcedor, o qual contribui espontaneamente e investe efetivamente no time (ITAÚ BBA, 2016).

O PST é uma alternativa financeira que ameniza a dependência dos times de receitas advindas de bilheteria e vendas de passes de jogadores. Gaspar et al. (2014) analisou cinco clubes nacionais possuidores de Programas Sócios Torcedores e, apesar de cada time possuir seus próprios modelos de planos, foram encontrados benefícios similares entre os pacotes oferecidos, tais como, descontos e a possibilidade de adquirir ingressos antecipadamente, acumulo de pontos para serem trocados por descontos em lojas e a aquisição de ingressos via internet. No período em questão, o patrocinador máster e o Programa Sócio Torcedor foram expressivos para as receitas anuais dos times.

Ademais se deve destacar que as receitas advindas da bilheteria são inconstantes, justamente pela presença dos torcedores nos estádios ser influenciada pelo desempenho dos times nos campeonatos. Além disso, os torcedores mais evolvidos, torcedores fiéis, são os que mais frequentam os estádios, mas esse grupo de torcedores é apenas uma parcela do total. Portanto, se os clubes trabalharem de forma mais eficaz com seus Programas Sócio Torcedor, poderão conseguir um aumento significativo das receitas e redução da variabilidade em seus fluxos de caixa (CARDOSO; SILVEIRA, 2014).

O futebol é o esporte mais popular do Brasil e possui uma significativa movimentação econômica gerada pelos clubes, atletas, entidades reguladoras e torcedores em todo o país. Os clubes captam recursos de maneiras distintas, tais como venda de camisas e outros produtos, por meio da venda de ingressos para os jogos, com aumento no número dos Programas Sócio Torcedor, com patrocinadores, além de ser responsável por impulsionar os contratos de direitos de transmissão dos jogos pelas redes de televisão (FIGUEIREDO; SANTOS; CUNHA, 2016).

Devida à significativa proporção que o futebol alcançou, tornou-se necessário estimular uma maior responsabilidade na gestão dos clubes, principalmente em seus aspectos financeiros. A Federação Internacional de Futebol - FIFA determinou que a Confederação Sul-Americana de Futebol CONMEBOL editasse um regulamento de licença para ser base das federações afiliadas, entre elas a brasileira, CBF. Em tais regulamentos também existem critérios relacionados a aspectos esportivos, de infraestrutura, jurídicos e administrativos. Entre os tipos de requisitos a serem abrangidos, estão os relacionados ao cumprimento da legislação nacional, atendimento às normas da FIFA e condições para o fornecimento de licença para participação em competições (MARQUES; COSTA, 2016).

Tal modalidade pode ser tratada como um grande negócio, pois considerando definições brasileiras, sulamericanas e europeias de micro, pequenas e médias empresas, os clubes desta modalidade são grandes instituições com o volume de faturamento superior ao das organizações citadas. Entretanto, os mais valiosos clubes de futebol analisados por Gasparetto (2013) que inclui times nacionais e estrangeiros, possuem baixa representatividade financeira perante o mercado econômico mundial, uma vez que existe uma grande a diferença entre os rendimentos desse esporte e as grandes atividades empresariais do mundo. 


\section{Redes bayesianas e análise conjunta}

Redes Bayesianas trata-se de uma técnica que reflete as possíveis dependências entre as variáveis analisadas de forma que os resultados são influenciados em termos de frequência dos acontecimentos, sendo necessário que as dependências sejam claramente definidas. Portanto, é imprescindível ter um apoio teórico referente ao conteúdo das variáveis e, a partir dessas informações, é possível apresentar soluções que podem auxiliar os interessados a decidirem o que fazer com o resultado disponível e, assim, optar por uma escolha com mais confiança. O método busca tentar prever direções com pressupostos de que os envolvidos estão inter-relacionados (MALAGRINO; ROMAN; MONTEIRO, 2018).

A análise de redes é uma abordagem útil para estudar a interconectividade de atores, individuais ou coletivos, em processos sociais, tais como fluxos de comunicação ou situações de tomada de decisão (HIRSCHI, 2010). Facilitam a identificação de interações entre variáveis, permitindo a estimação de relações importantes e fornecendo insights de acordo com a conectividade (BRIGANTI et al., 2018).

As redes bayesianas são utilizadas para representar a relação entre as variáveis de maneira legível, ao mesmo tempo em que leva em conta as distribuições de probabilidade e a independência. Portanto, podese usar uma rede Bayesiana para responder questões relativas a qualquer variável abrangida nesta distribuição (SARDINHA; PAES; ZAVERUCHA, 2018).

O princípio das redes bayesianas é baseado no teorema de Bayes, que utiliza a probabilidade de um sistema com base na ocorrência de um evento atual (DAHIRE, et al., 2018). É possível determinar quais variáveis na rede bayesiana podem influenciar o valor de outra: se existe uma trilha ativa entre um par de variáveis, então elas não são independentes; caso contrário, se todos os caminhos entre eles estiverem bloqueados, eles serão condicionalmente independentes uns dos outros (SARDINHA; PAES; ZAVERUCHA, 2018).

Assim como as redes bayesianas, a análise conjunta também utiliza probabilidades, porém, com o intuito de investigar as características de decisões de compra a respeito de um produto ou serviço. A técnica promete auxiliar na compreensão das escolhas dos consumidores, indicando quais os atributos são considerados mais importantes e qual combinação (entre atributos e níveis) é a mais preferível (NURAENI; NOVANI; ARRU, 2015). Dessa forma, as organizações podem elaborar ofertas mais apropriadas para o seu público alvo em posse dos resultados dessa análise estatística.

Análise conjunta é um termo genérico usado para descrever uma técnica que busca identificar preferências. As origens dessa análise estatística são principalmente associadas às pesquisas que buscam representar matematicamente o ranking dos comportamentos observados de manipulações sistemáticas e fatorial de atributos. Os métodos de análise conjunta dependem de provas formais sobre as representações matemáticas e das classificações de matrizes ortogonais (LOUVIERE; FLYNN; CARSON, 2010).

Por conseguinte, a análise conjunta será empregada nesse trabalho como base para complementar os resultados que serão obtidos com as redes bayesianas.

\section{Procedimentos metodológicos}

Trata-se de uma pesquisa de natureza descritiva e quantitativa. Os dados foram coletados por um survey virtual de autopreenchimento elaborado em duas etapas, onde primeiramente o respondente avaliava dentre os PSTs reais do seu time favorito qual era o plano que estaria mais propenso a adquirir e em seguida avaliava da mesma maneira, utilizando uma escala Likert de 10 pontos, 16 planos fictícios.

Os planos fictícios foram elaborados para estimativas da análise conjunta. Tais planos foram derivados dos benefícios identificados nos PSTs dos 20 times classificados na série A do Campeonato Brasileiro de Futebol de 2016 os quais foram resumidos em seis (6) atributos principais, alguns de nível nominal e 
outros de nível intervalar. Usando os valores típicos encontrados nos PSTs determinou-se a quantidade e os valores dos níveis para cada atributo.

Optou-se por um delineamento fatorial fracionário para as combinações de estímulos, pois, como se tratou de 6 atributos, sendo 3 com 3 níveis e os 3 restantes com 2 níveis, seria inviável optar pela abordagem de perfil completo, pois o instrumento ficaria com 72 estímulos $\left(3^{3} \times 3^{2}\right)$ o que exigiria maior tempo e esforço do respondente, prejudicando a taxa e a qualidade das respostas.

Figura 1- Construtos utilizados no instrumento

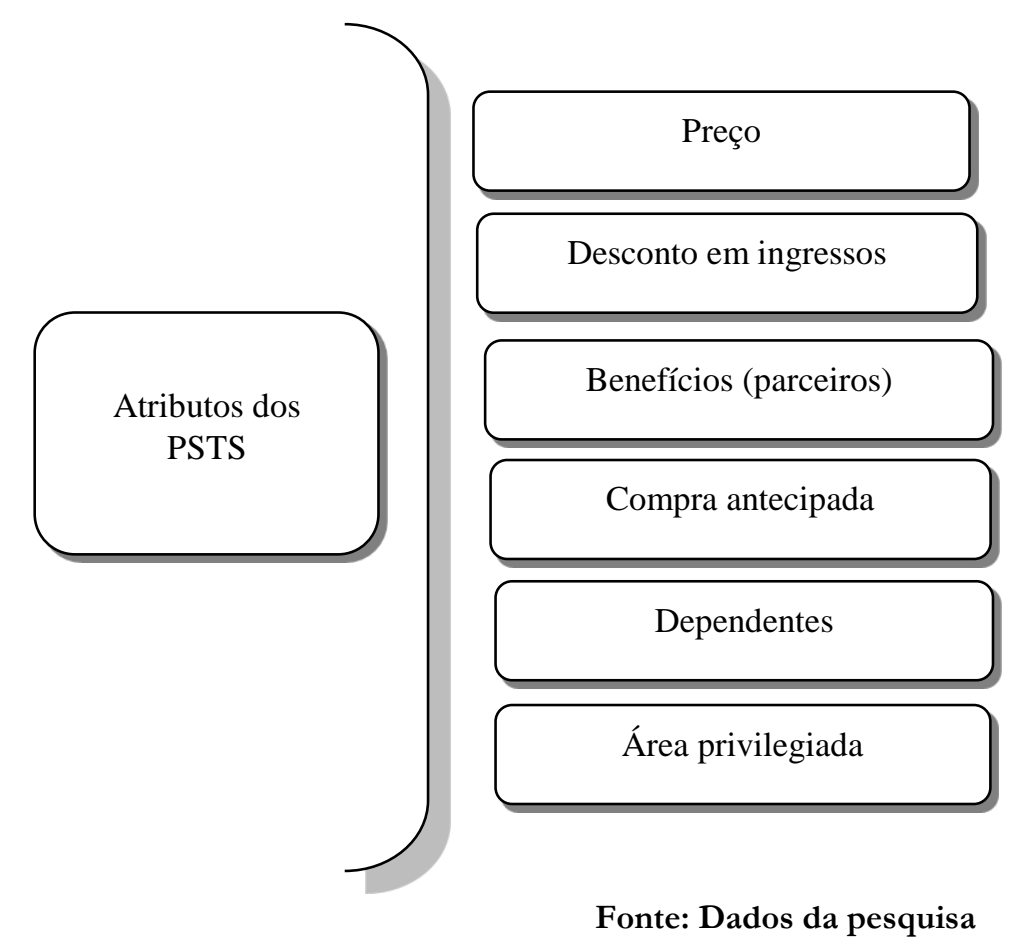

A Figura1 apresenta os seis (6) construtos adotados. Para o preço apresentou-se aos respondentes os níveis 20, 40, 100 e 140 reais. O desconto nos ingressos tinha as opções de 30\%, 60\% e 90\%. Já os benefícios, que se trata de parcerias onde o associado possui algum benefício de acordo com seu plano, as opções foram "movimento por um futebol melhor", "desconto em rede de parceiros" e "desconto em lojas oficiais". Quanto a compra antecipada, assim como a área privilegiada, o respondente apenas opinava sim ou não, e o construto dependentes possuía os níveis 1, 2 ou 3 associados.

Adotou-se a amostragem por conveniência e definiu-se o tamanho da amostra por um cálculo amostral. Após a realização dos cálculos encontrou 385 como valor mínimo para a amostra, a qual possui 436 observações válidas. A população foi composta por torcedores dos 20 times classificados na série A do Campeonato Brasileiro de Futebol de 2016.

Realizou-se um pré-teste com pessoas com as mesmas características da amostra para verificar irregularidades que pudessem dificultar a interpretação do questionário. Os pontos questionados foram modificados e reaplicados os pré-testes. Em seguida verificou se a etapa da análise conjunta estava coerente e seguiu para coleta definitiva. O questionário foi aplicado pelo aplicativo Survey Monkey ${ }^{\mathbb{B}}$ através de um link enviado para e-mails, grupos em redes sociais, e também grupos do aplicativo WhatsApp ${ }^{\circledR}$ relacionados aos clubes de futebol selecionados.

O questionário foi elaborado de maneira que só avançaria para página seguinte o pesquisado que respondesse todas as questões. Dessa forma, não foi possível utilizar as respostas incompletas para um tratamento de dados ausentes. Dos 584 respondentes, 87 interromperam o questionário, correspondendo a 14,9\% de toda a base. Além disso, 43 respondentes avaliaram os 16 planos fictícios com a mesma nota, 
tornando a estimação pela análise conjunta impossível (pois a variável dependente $\mathrm{Y}$ se torna uma constante). Esses casos também foram removidos da amostra, correspondendo a 7,3\% dos questionários. Foram encontradas 6 observações atípicas sendo todos outliers positivos. Tais respostas também foram excluídas das análises. No total, a perda de dados correspondeu a $22 \%$ da base original.

Além disso, empregou-se a medida de correlação de Kendall, a qual sinaliza se existe um consenso entre as respostas originais e as estimadas pelo modelo, para verificar a validade da análise conjunta. Aplicouse um nível de significância de 5\% ( $\mathrm{p}<0,05)$ para essa finalidade (BENITEZ; GOLINSKI, 2007). Tradicionalmente, o ponto de corte do valor-p para rejeitar a hipótese nula é de 0,05 (FERREIRA; PATINO, 2015). Foram encontrados doze resultados não significativos os quais foram excluídos. As análises descritas foram feitas pelo software estatístico SPSS 17.0®.

Com os resultados obtidos nessa etapa, definiu-se um modelo baseado em rede bayesiana capaz de prever/identificar a característica sociodemográfica, o atributo e o plano ideal de acordo com a combinação selecionada. Foi desenvolvido utilizando o software Netica ${ }^{\circledR}$ e resultou em uma rede com quinze nós: gênero, faixa etária, estado civil, escolaridade, renda familiar, 5 nós de atributos e 5 nós de planos (os 16 fictícios elaborados com a análise conjunta). As arestas foram direcionadas dos nós das características sociodemográficas para os atributos e dos atributos para os planos. A tabela de valores da rede foi preenchida utilizando pesos proporcionais aos resultados da primeira etapa.

\section{Apresentação e análise dos resultados}

A predominância na amostra foi da faixa etária entre 18 a 29 anos, solteiros, residentes em Minas Gerais, com ensino superior, renda familiar entre $\mathrm{R} \$ 2.041,00$ a $\mathrm{R} \$ 5.100,00$ e do sexo masculino. Tais resultados foram influenciados pelo ciclo social da pesquisadora, pois se tratou de uma amostra por conveniência.

Os atributos com seus respectivos níveis foram avaliados em um subconjunto por seu valor parcial perante aos torcedores, possibilitando saber não apenas o quão relevante cada atributo é, mas também a importância de cada nível. Para fins do presente estudo consideraram-se as utilidades parciais. A importância relativa de cada atributo foi inicialmente executada individualmente e posteriormente agregadas para se obter um resultado geral (HAIR, JR. et. al 2005).

Os resultados indicaram que para a amostra geral o atributo percebido com o maior valor para os pesquisados é o "Preço", e o nível "R $\$ 20,00 "$ foi o que apresentou o maior peso relativo de importância. Hinterhuber (2004) argumenta que a percepção de valor do consumidor em relação a um serviço interfere no preço que o mesmo está disposto a pagar. A necessidade de alta qualidade nos serviços surgiu como um antecedente da percepção de valor. Portanto, é necessário compreender as maneiras de interpretação do que constitui em uma oferta de valor na percepção do usuário, pois os consumidores se tornaram mais seletivos com as ofertas, analisando o custo total e não apenas o monetário (BERRY; ZEITHAML; PARASURAMAN, 1985). Em seguida, o atributo "Descontos nos ingressos" recebeu a maior importância, e o nível " $90 \%$ " foi o mais impactante. Dentre seus variados benefícios, os PSTs têm como principal objetivo oferecer ingressos com desconto, o que se caracteriza como uma boa opção para clubes que, geralmente, não preenche todos os assentos nos estádios, fator que está mais associado ao momento esportivo vivido pelo time (ITAÚ BBA, 2016). Tais descontos estimulam a presença dos torcedores nos jogos.

$\mathrm{Na}$ sequência verificou-se que o construto "Benefícios" recebeu maior importância, sendo o "Desconto em rede de parceiros" o nível preferido. De acordo com Martins (2016) no Brasil, um dos principais apoiadores dos Programas Sócios Torcedores é o Movimento por um Futebol Melhor. Tal apoiador tem como objetivo alavancar os programas dos clubes no país por meio do oferecimento de descontos em produtos e serviços de diversas marcas aos torcedores. Portanto, nota-se que os níveis "Desconto em rede de parceiros" e "Movimento por um futebol melhor", os quais foram identificados como níveis de 
maior e menor interesse respectivamente, têm finalidades semelhantes, logo os resultados sugerem que uma vez que se tem preferência por um deles o outro não é tão relevante.

Portanto, esses achados demonstram que as preferências dos torcedores variam, sendo necessário identificar quais são as estratégias mais eficientes para cada plano. Os PSTs são modelos que utilizam tanto a aboradagem de acúmulo de pontos como a de nível de consumidor, sendo esses os formatos mais populares de programa de fidelidade. Dessa forma, quando for identificado um torcedor que apresenta forte orgulho pelo time, por exemplo, trata-se de emoções propensas a terem maior impacto nos modelos de nível de consumidor, pois fornecem a oportunidade de sinalizar um status, o que é consistente com a função de orgulho (SEPTIANTO; AN; CHIEW; PARAMITA; TANUDHARMA, 2019).

A "Compra Antecipada" foi identificada como o quarto benefício de maior importância, tratando-se de um atributo sem níveis de diferenciação, ou seja, o respondente apenas opinava "sim" ou "não". O atributo refere-se à possibilidade de adquirir ingressos antes que os torcedores não sócios possam comprar, o que se torna atrativo para jogos importantes, como finais de grandes campeonatos, pois a procura na bilheteria, geralmente, é maior. Além disso, também tem sido considerado vantajoso para os clubes, já que o torcedor ao se tornar sócio se compromete a pagar uma mensalidade tendo, muitas vezes, a possibilidade de comprar ingressos antecipadamente. Nesse sentido, a compra antecipada é um valor referente à antecipação da receita com bilheteria e em jogos de pouca presença de torcedores parte da receita dos ingressos já estará garantida com o pagamento das mensalidades dos sócios (ITAÚ BBA, 2016).

Subsequentemente, o atributo melhor avaliado foi a possibilidade de incluir dependentes, sendo " 3 dependentes" o nível melhor avaliado. A amostra do presente estudo foi composta por $62,2 \%$ de solteiros e tal atributo torna-se mais atraente para pessoas que têm filhos que na maioria das vezes são pessoas casadas, divorciadas ou viúvas. O envolvimento familiar no contexto do futebol no Brasil é muito frequente, sendo tal ligação identificada, por exemplo, na notável a influência que os pais exercem na escolha do time favorito dos filhos (MACAGNAN; BETTT, 2014). Por último, o atributo "Acesso à Área Privilegiada" foi o que despertou o menor interesse em comparação aos demais.

Portanto, o envolvimento familiar no contexto do futebol é um fator favorável para estratégias do mercado esportivo. Um exemplo disso são os resultados de ações boca a boca, pois, possivelmente, um torcedor comunicará sua experiência a outras pessoas próximas. Um torcedor insatisfeito com avaliações cumulativa dos desempenhos anteriores e com a probabilidade de insatisfação futura, terá um aumento na disposição de alertar as pessoas para não relacionar com a organização envolvida ( WEITZL; HUTZINGER; EINWILLER, 2018).

Os resultados demonstraram que os planos com menores preços e maiores descontos nos ingressos têm maior intenção de compra, mesmo que não se tenha acesso à área privilegiada. Entretanto, ao analisar os resultados de forma estratificada nota-se que existem preferências diferentes. Portanto, em um contexto com uma significativa variedade de torcedores, torna-se fundamental conhecê-los, para que suas necessidades distintas sejam melhor mapeadas.

Nesse sentido, deve-se considerar que o valor é um construto multidimensional e suas diversas possibilidades.Valores funcionais, sociais, emocionais, epistêmicos e condicionais, compõem as diversas possibilidades de combinações para a decisão de compra e, consequentemente, para construção de novas propostas de valor e elaboração de planos para PSTs (SHETH; NEWMAN; GROSS, 1991).

O quadro 1 apresenta a porcentagem de importância para cada atributo por diferentes características sociodemográficas. Para avaliar se existem diferenças significativas entre as estatísticas apresentadas, utilizou-se o método de Análise de Variância - ANOVA que é empregado para avaliar a diferença entre as médias de grupos. Dessa forma, verificou se a hipótese nula testada é a igualdade de médias da variável dependente ao longo dos grupos (HAIR, JR. et. al 2005). Considerou-se para a hipótese nula que todas 
as médias são iguais e para a hipótese alternativa que ao menos uma é diferente. Portanto, todos os $(\mathrm{P}<$ $0,05)$ foram considerados significativos. Esses resultados foram transformados em pesos proporcionais e utilizados para definir o valor table na rede bayesiana que desenvolveu o modelo proposto nesse artigo.

Quadro 1 - Porcentagens de importância por características sociodemográficas

\begin{tabular}{|c|c|c|c|c|c|c|c|}
\hline \multirow{2}{*}{\multicolumn{2}{|c|}{$\begin{array}{l}\text { CARACTERÍSTICAS } \\
\text { SOCIODEMOGRÁFICAS }\end{array}$}} & \multicolumn{6}{|c|}{ ATRIBUTO EM ORDEM DE IMPORTÂNCIA } \\
\hline & & \multirow{3}{*}{$\begin{array}{c}\text { Preço } \\
22 \% \\
23 \% \\
\end{array}$} & \multirow{3}{*}{$\begin{array}{c}\begin{array}{c}\text { Desconto } \\
\text { no } \\
\text { ingresso }\end{array} \\
21 \% \\
22 \% \\
\end{array}$} & \multirow{3}{*}{$\begin{array}{c}\text { Benefícios } \\
19 \% \\
18 \% \\
\end{array}$} & \multirow{3}{*}{$\begin{array}{c}\begin{array}{c}\text { Compra } \\
\text { antecipada }\end{array} \\
15 \% \\
17 \% \\
\end{array}$} & \multirow{3}{*}{$\begin{array}{c}\text { Dependentes } \\
15 \% \\
13 \% \\
\end{array}$} & \multirow{3}{*}{$\begin{array}{c}\begin{array}{c}\text { Área } \\
\text { privilegiada }\end{array} \\
8 \% \\
7 \%\end{array}$} \\
\hline Gênoro & Feminino & & & & & & \\
\hline Genero & Masculino & & & & & & \\
\hline \multirow{5}{*}{ 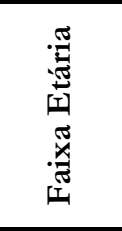 } & Até 17 anos & $15 \%$ & $19 \%$ & $20 \%$ & $18 \%$ & $15 \%$ & $13 \%$ \\
\hline & $18-29$ anos & $21 \%$ & $24 \%$ & $18 \%$ & $15 \%$ & $13 \%$ & $9 \%$ \\
\hline & $30-39$ anos & $23 \%$ & $20 \%$ & $18 \%$ & $17 \%$ & $14 \%$ & $8 \%$ \\
\hline & $40-49$ anos & $29 \%$ & $18 \%$ & $17 \%$ & $15 \%$ & $15 \%$ & $6 \%$ \\
\hline & 50 anos ou mais & $24 \%$ & $18 \%$ & $20 \%$ & $17 \%$ & $15 \%$ & $6 \%$ \\
\hline \multirow{4}{*}{ 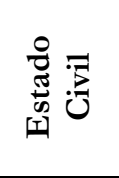 } & Solteiro (a) & $22 \%$ & $23 \%$ & $18 \%$ & $16 \%$ & $13 \%$ & $8 \%$ \\
\hline & Casado (a) & $23 \%$ & $20 \%$ & $17 \%$ & $16 \%$ & $15 \%$ & $9 \%$ \\
\hline & Viúvo (a) & $11 \%$ & $41 \%$ & $20 \%$ & $8 \%$ & $11 \%$ & $9 \%$ \\
\hline & Divorciado (a) & $24 \%$ & $19 \%$ & $23 \%$ & $14 \%$ & $15 \%$ & $5 \%$ \\
\hline \multirow{5}{*}{ 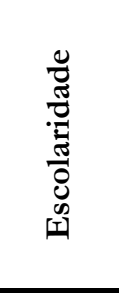 } & $\begin{array}{l}\text { Fundamental } \\
\text { incompleto }\end{array}$ & $15 \%$ & $25 \%$ & $24 \%$ & $14 \%$ & $18 \%$ & $4 \%$ \\
\hline & Médio incompleto & $15 \%$ & $20 \%$ & $16 \%$ & $18 \%$ & $17 \%$ & $14 \%$ \\
\hline & Ensino médio & $21 \%$ & $19 \%$ & $21 \%$ & $13 \%$ & $15 \%$ & $11 \%$ \\
\hline & Superior incompleto & $22 \%$ & $24 \%$ & $18 \%$ & $14 \%$ & $14 \%$ & $8 \%$ \\
\hline & Ensino superior & $23 \%$ & $21 \%$ & $18 \%$ & $17 \%$ & $14 \%$ & $7 \%$ \\
\hline \multirow{7}{*}{ 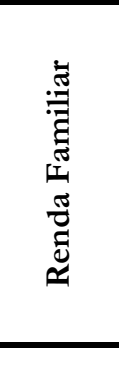 } & Até $1.020,00$ & $16 \%$ & $24 \%$ & $23 \%$ & $10 \%$ & $18 \%$ & $9 \%$ \\
\hline & $\begin{array}{c}\text { De } 1.021,00 \text { até } \\
2.040,00\end{array}$ & $21 \%$ & $23 \%$ & $21 \%$ & $12 \%$ & $14 \%$ & $9 \%$ \\
\hline & De $2.041,00$ até & $240 /$ & $20 \%$ & 100 & & & \\
\hline & De 5.101 até & $24 \%$ & $\angle 2 \%$ & $18 \%$ & $15 \%$ & $13 \%$ & \\
\hline & $10.020,00$ & $23 \%$ & $21 \%$ & $18 \%$ & $17 \%$ & $14 \%$ & $7 \%$ \\
\hline & Acima de $10.021,00$ & $21 \%$ & $21 \%$ & $17 \%$ & $19 \%$ & $14 \%$ & $8 \%$ \\
\hline & Resultado Geral & $22 \%$ & $22 \%$ & $18 \%$ & $16 \%$ & $14 \%$ & $8 \%$ \\
\hline
\end{tabular}

Fonte: Dados da pesquisa

Nota-se que há pouca diferença na importância entre homens e mulheres pelos atributos da pesquisa. Os atributos "Preço", "Desconto nos Ingressos" e "Compra Antecipada" alcançaram uma importância maior para homens, enquanto os atributos "Dependentes", "Área Privilegiada" e "Benefícios" foram mais importantes na opinião das mulheres. Porém as diferenças não ultrapassaram $2 \%$.

Para faixa etária, o preço e o desconto nos ingressos continuaram sendo os atributos mais valorizados pelos os respondentes, exceto para os com idade até 17 anos, porém tal faixa etária é pouco representativa na presente amostra, correspondendo a apenas $1 \%$ da base total de dados. Contudo, os construtos "Dependentes" e "Área Privilegiada" continuaram como os menos atrativos para a intenção de compra de um plano sócio torcedor.

Sequencialmente, a divisão por estado civil também teve o preço como o atributo mais valorizado pelos respondentes, exceto pelos viúvos, porém, assim como ocorreu para faixa etária de até 17 anos, tais respondentes são pouco representativos na presente amostra, correspondendo a apenas $0,5 \%$ da base 
total de dados. Contudo, o construto "Área Privilegiada" continuou como o menos atrativo para a intenção de compra de um plano sócio torcedor.

Quanto à escolaridade, notou-se que o preço e o desconto nos ingressos também foram os atributos mais valorizados pelos respondentes, exceto pelos que possuem apenas Ensino Médio cuja preferência é pelo construto "Benefícios". O construto "Área Privilegiada" continuou como o menos atrativo para a intenção de compra. Observou-se que os respondentes com Ensino Médio Incompleto foram os que mais se distanciaram da média dos resultados gerais, cuja representatividade na amostra é de 1,4\%.

Seguindo a mesma linha, nos resultados por Renda Familiar o preço e o desconto nos ingressos continuaram sendo os atributos mais valorizados pelos respondentes e o construto "Área Privilegiada" manteve-se como o menos atrativo para a intenção de compra de um plano Sócio Torcedor. Observouse também que os respondentes com renda até $\mathrm{R} \$ 1.020,00$ foram os que mais distanciaram da média dos resultados gerais.

O modelo desenvolvido com a rede bayesiana permite três tipos de previsão: por característica sociodemográfica por atributo e por plano. Portanto, de acordo com as dependências entre as variáveis, a frequência dos acontecimentos e a partir de um apoio teórico, é possível apresentar soluções que podem auxiliar os interessados a optarem por uma escolha com mais segurança (MALAGRINO; ROMAN; MONTEIRO, 2018). Ao observar a linhas selecionada de um dos nós de característica sociodemográfica, é possível visualizar as probabilidades de preferências dos atributos e o plano mais adequado. Tal indicação ocorre em função do plano possuir os atributos mais valorizado pelo segmento. $\mathrm{Na}$ Figura 2 ao selecionar "29 a 39" no nó "faixa etária" nota-se o preço como atributo mais valorizado com valor de $23 \%$ e o plano 7 sendo o mais adequado para esse contexto. A característica sociodemográfica influenciará na preferência do atributo que por sua vez influenciará no plano ideal, conforme demonstra a direção das arestas.

Figura 2- Modelo de pesquisa previsão por característica sociodemográfica

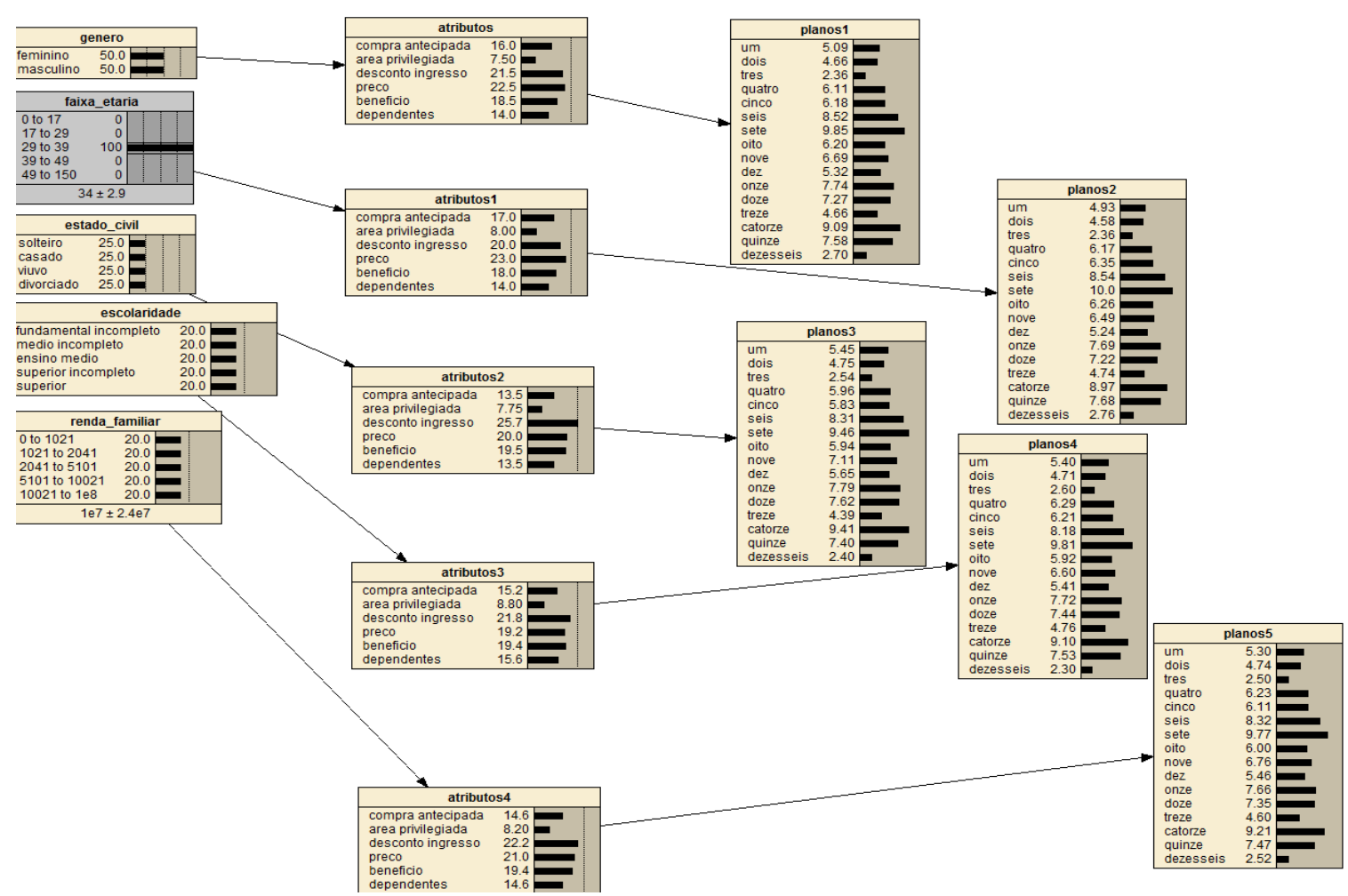

Fonte: dados da pesquisa 
De modo semelhante, ao observar a linha selecionada de um dos nós "atributos" é possível visualizar as probabilidades de preferência sociodemográfica e o plano mais adequado. Tal indicação ocorre em função do plano possuir as características do segmento que mais valoriza o atributo escolhido. A análise de redes é uma abordagem útil para estudar a interconectividade de atores, individuais ou coletivos, em processos sociais (HIRSCHI, 2010). É possível determinar quais variáveis na rede bayesiana podem influenciar o valor de outra analisando se existe uma trilha ativa entre as variáveis (SARDINHA; PAES; ZAVERUCHA, 2018). Na Figura 3 ao selecionar "desconto no ingresso" no nó "atributos 2" nota-se que os viúvos são os que mais valorizam o atributo sendo os planos 9,11, 12 e 14 os que podem ser adequados a esse contexto.

Figura 3- Modelo de pesquisa previsão por atributo

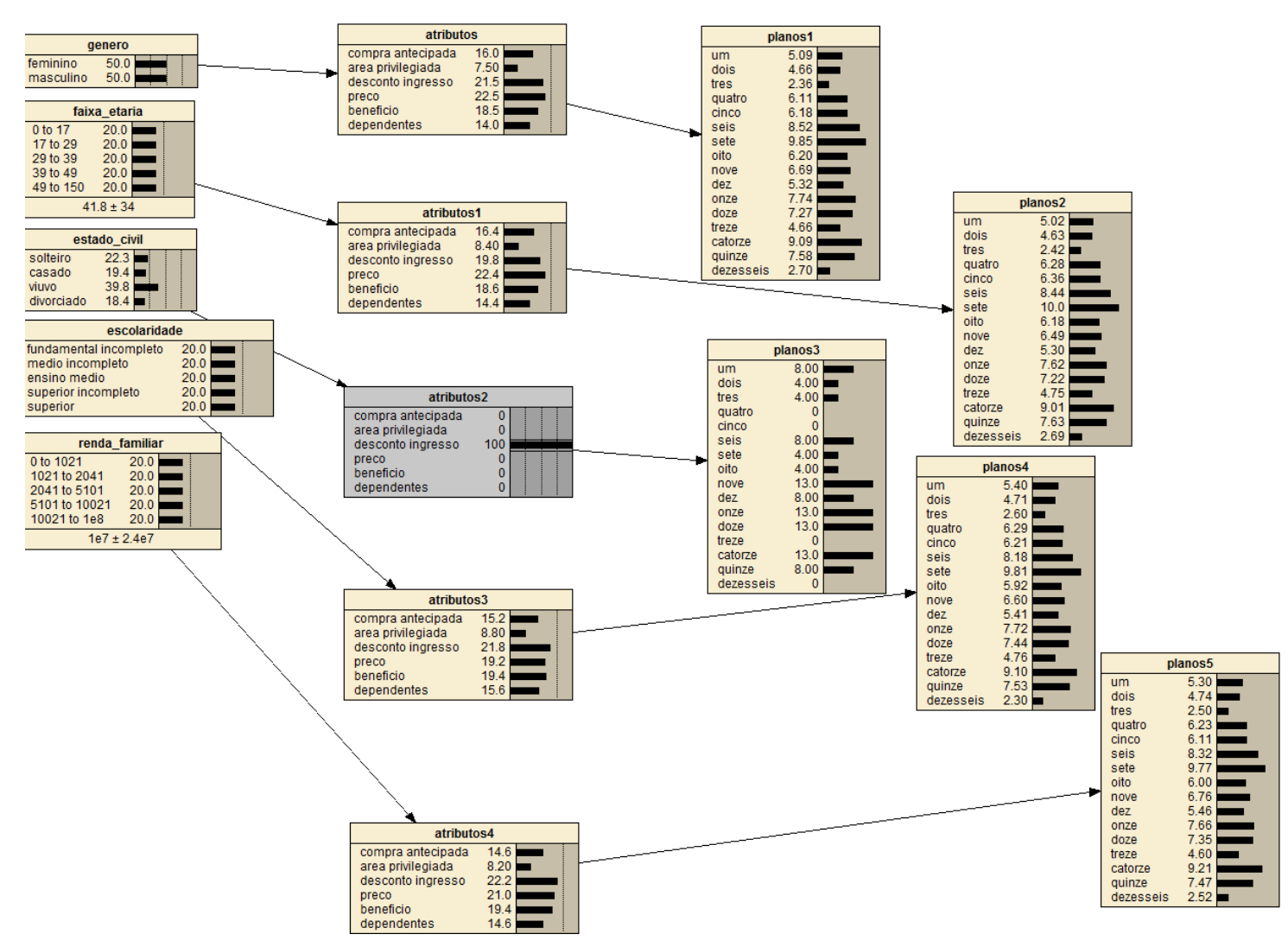

Fonte: dados da pesquisa

Ao observar a linha selecionada dos nós "planos" é possível visualizar as probabilidades das preferências sociodemográficas e dos atributos. Tal indicação ocorre para demonstrar quais são os atributos e características sociodemográficas mais adequadas para o plano escolhido. A Figura 4 demonstra o caso de haver interesse nos atrativos considerados mais importantes para um plano específico. Para verificar todos os níveis sociodemográficos, será necessário selecionar o plano em questão em todos os nós "planos" para assim obter um resultado conjunto. Por exemplo, para o plano "onze" seria mais interessante para o público masculino (50,5\%), com faixa etária de 18 a 29 anos (20,3\%), viúvos (26,7\%), com ensino fundamental incompleto (21\%) e renda familiar de $\mathrm{R} \$ 10.021$ ou mais $(20,8 \%)$. 
Figura 4- Modelo de pesquisa previsão por plano

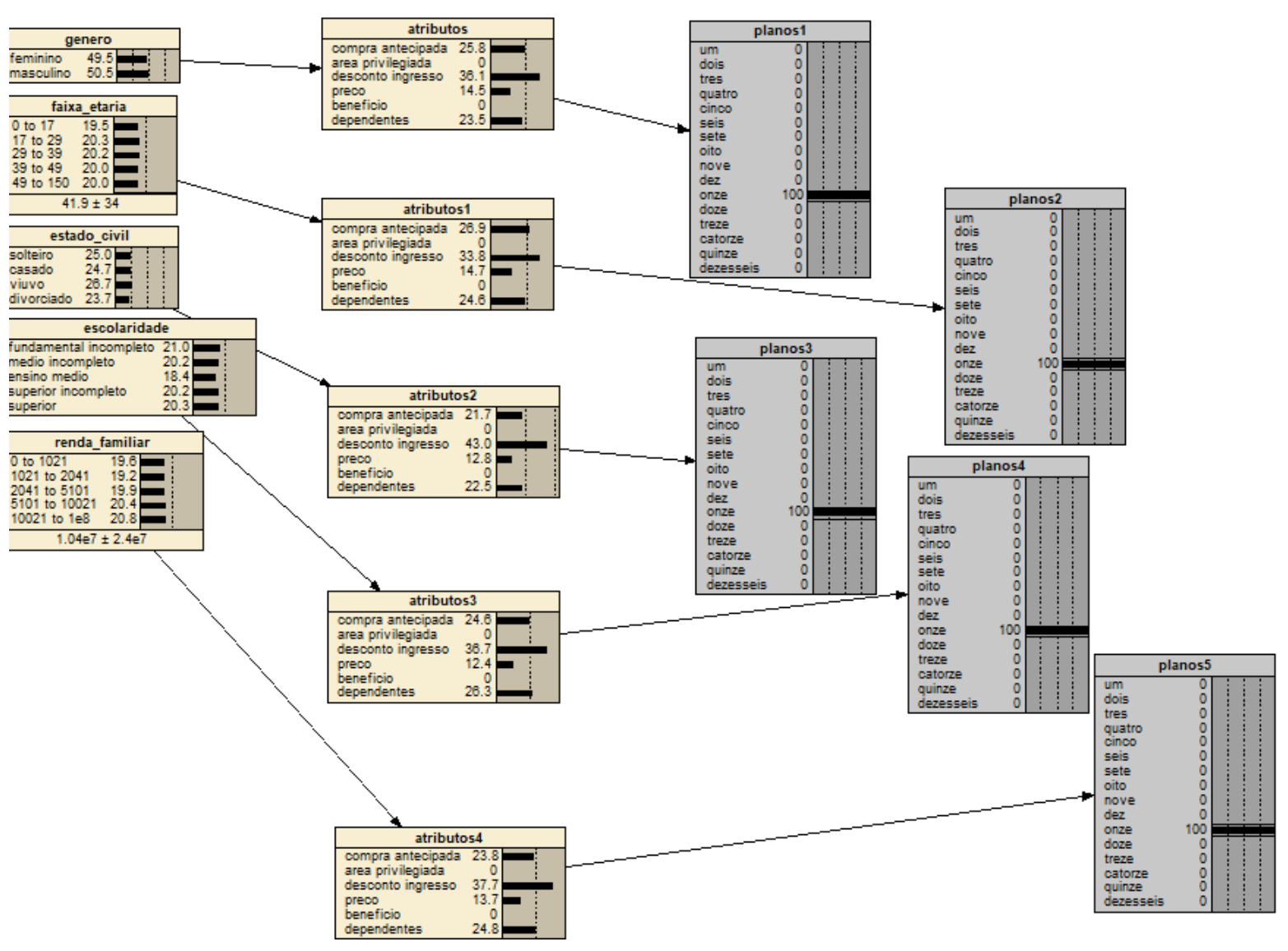

Fonte: dados da pesquisa

\section{Considerações finais}

O estudo apresentou evidências de que para a amostra geral o atributo "Preço" desempenha um significativo impacto na decisão de compra e na percepção de valor nos planos dos PSTs. O "Desconto nos ingressos" foi o segundo atributo mais significativo, o qual é considerado pela literatura um dos principais objetivos de um PST (ITAÚ BBA, 2016). O "Descontos em redes de parceiros", foi o nível mais valorizado no construto "Benefício", seguido da "Compra antecipada", inclusão de 3 dependentes, e por último o acesso à área privilegiada.

Embora os consumidores tenham se tornado mais seletivos com as ofertas, analisando o custo total e não apenas o monetário, fica evidente que o financeiro ainda tem forte influência e a percepção de valor interfere no preço que os torcedores estão dispostos a pagar.

Os resultados por características sociodemográficas apontam que há pouca diferença na preferência entre homens e mulheres. Contudo os atributos relacionados a valores financeiros (preço, desconto nos ingressos e compra antecipada) apresentam maior importância para os homens. Enquanto os atributos referentes à comodidade (dependentes, área privilegiada e benefícios) foram mais importantes na opinião das mulheres.

Logo, essas evidências reforçam que as preferências dos torcedores variam, sendo necessário identificar quais são as estratégias mais eficientes para cada plano. Além de oferecer planos com opções de acúmulo de pontos e de nível de consumidor, também é válido considerar alternativas para os torcedores selecionarem os próprios atributos de interesse. 
Já para faixa etária, foram encontradas diferenças expressivas. Para os respondentes de até 17 anos o "Benefício" foi o atributo mais valorizado, os que se encontravam na faixa entre 20 a 29 anos atribuíram maior valor ao "Desconto nos Ingressos". Todos os pesquisados com 30 anos ou mais avaliaram o "Preço" como o atributo de maior valor. O atributo "Desconto nos ingressos" foi o que resultou em maior divergência de opiniões entre as faixas etárias.

Nas comparações por estado civil, os solteiros valorizam mais o "Desconto nos ingressos", enquanto os divorciados e casados priorizam o "Preço". Os viúvos avaliaram o "Benefício" como atributo de maior importância. O atributo "Desconto nos ingressos" foi o que apresentou maior divergência de opiniões comparando-se com os outros atributos dessa característica sociodemográfica.

Quanto à Escolaridade, verificou-se que os participantes que possuíam Ensino Médio completo melhor avaliaram o construto "Benefícios", os com Ensino Superior completo o "Preço", e os com Ensino Médio incompleto e Ensino Superior incompleto deram maior importância para o "Desconto nos ingressos". Não foram incluídos os participantes que informaram possuir ensino fundamental e ensino fundamental incompleto, pois juntos representavam apenas 1,6\% da base total de dados.

Nos resultados por Renda Familiar, verificou-se que para os com receita até $\mathrm{R} \$ 1.020,00$ o "Desconto nos ingressos" foi o atributo de maior importância e conforme a renda aumentava o "Preço" passava a ser o atributo mais valioso, exceto para os respondentes com renda acima de $\mathrm{R} \$ 10.021,00$ que atribuíram à mesma importância a ambos os atributos. Portanto, os que possuíam renda até $\mathrm{R} \$ 2040,00$ deram maior importância para o desconto nos ingressos e os que se encontravam na faixa de $\mathrm{R} \$ 2041,00$ a $\mathrm{R} \$ 10.020$ para o preço. O atributo "Compra Antecipada" foi o que resultou em maior divergência de opiniões comparando-se com os outros atributos dessa característica sociodemográfica.

No que se refere ao construto "Dependente", que foi avaliado na amostra geral como o penúltimo na preferência, sugere a premissa de que tal fato pode ter ocorrido em função do grande número de solteiros presentes na amostra $(62,2 \%)$, pois o interesse por planos com a opção de incluir familiares desperta o interesse de pessoas que têm filhos, o que é mais frequente entre pessoas casadas, divorciadas e viúvas. Tal premissa se torna mais convincente observando os resultados estratificados por estado civil, pois a maior média de importância no construto em questão foi a dos respondentes casados, seguido dos divorciados e tendo os solteiros como últimos na preferência.

Ademais, fica evidente a necessidade dos gestores esportivos aprimorarem suas estratégias de marketing de relacionamento, investindo e diversificando os planos dos PSTs, fortalecendo as relações de satisfação e confiança. Embora, de maneira geral, o preço e o desconto nos ingressos tenham sido os atributos mais valorizados, as peculiaridades encontradas reforçam a necessidade de considerar que o valor é um construto multidimensional com diversas possibilidades para compor os planos dos PSTs.

No que se refere ao modelo proposto a partir da rede bayesiana, nota-se ser uma ferramenta adequada para complementar a análise conjunta, pois ambas utilizam probabilidades em suas bases: a análise conjunta para estimar os cartões (produto/serviço fictício) e a rede bayesiana para fazer previsões considerando a forma que os resultados são influenciados em termos de frequência dos acontecimentos.

Ademais, mostrou ser uma ferramenta útil para que gestores esportivos identifiquem os atributos mais adequados para seus planos de acordo com as características sociodemográficas de seus torcedores. Além disso, também foram demonstradas outras possibilidades, tais como, indicação em função do plano (Fig.4) e das características sociodemográficas (Fig.2). Portanto, de acordo com as dependências entre as variáveis, foi possível apresentar soluções que podem auxiliar os times a optarem por escolhas com mais segurança em seus PSTs.

Aponta-se como limitação principal do estudo a representatividade da amostra. Utilizou-se uma amostragem por conveniência e não se empregou medidas para que a mesma fosse estratificada. Dessa 
forma, a representatividade das características sociodemográficas dos torcedores ficou desequilibrada o que dificultou a comprovação de determinadas premissas, por exemplo, a preferência por um plano com dependentes. Também trouxe uma representação tendenciosa por região, já que a maioria dos respondentes reside no Sudeste e torcem por times dessa região.

Portanto, sugere-se para pesquisas futuras a adoção de uma amostragem estratificada, a fim de suavizar tais limitações, principalmente, considerando a influência que o envolvimento familiar tem no contexto do futebol e as consequências dessas relações. Por exemplo, possivelmente, um torcedor comunicará sua experiência a pessoas próximas, executando estratégias de comunicação boca a boca, as quais podem alertar ou recomendar a organização envolvida.

Dessa forma, o presente artigo contribuiu com a proposta de um mapeamento da estrutura de valor para ser aplicada aos PSTs de clubes de futebol. Quanto ao modelo desenvolvido com redes bayesianas, embora tenha se mostrado eficaz para identificar o melhor plano por atributo ou característica sociodemográfica, além de também ser útil para o caso contrário, ou seja, indicar qual o público alvo adequado para um plano que já possui seus atributos definidos, seria interessante condensar o modelo de forma que só houvesse um nó para "plano" e um nó para "atributo". Entretanto, para fazê-lo é necessário utilizar linguagens de programação, pois a interface gráfica do Netica ${ }^{\circledR}$ não possui tantos recursos personalizados. Desse modo, outra sugestão para trabalhos futuros seria a realização de parcerias interdisciplinares com programadores ou o conhecimento de outro software que ofereça mais recursos. Contudo, o artigo e o modelo apresentado podem ser úteis para estimular os gestores esportivos a buscarem tanto a compressão dos melhores benefícios para se oferecer, como para identificação dos pontos positivos de um PST.

\section{Referências}

AVANCINI, J., et al. Sport Club Internacional 100 anos, 100 mil sócios. ESPM Central de Cases, p. 2-14, 2010.

BENITEZ, R. M., GOLINSKI, I. A agricultura orgânica como estratégia alternativa em busca da sustentabilidade - Uma análise estatística da organização atual. Revista de Administração e Inovação, v. 4, n. 2, p. 117-132, 2007. DOI: 10.5380/dma.v41i0.49766.

BERRY, L. L, ZEITHAML, V. A., PARASURAMAN, A. Quality counts in services, too. Business Horizons, v.28, n. 3, p. 44-52, 1985. https://doi.org/10.1016/0007-6813(85)90008-4

BISCAIA, R., et al. Investigating the role of fan club membership on perceptions of team brand equity in football. Sport Management Review, v.19, n. 2, p. 157-170, 2016. DOI: https://doi.org/10.1016/j.smr.2015.02.001.

BRIGANTI, G., et al. Network analysis of empathy items from the Interpersonal Reactivity Index in 1973 young adults. Psychiatry Research, 2018. DOI: 10.1016/j.psychres.2018.03.082.

CARDOSO, M. V.; SILVEIRA, M. P. A importância da adoção do sócio torcedor como estratégia de inovação para aumentar as receitas dos clubes de futebol no Brasil. PODIUM Sport, Leisure and Tourism Review Edição Especial, v. 3, n. 3, p. 12-24, 2014. DOI: 10.5585/podium.v3i3.99.

CHANG, C., DIBB, S. Reviewing and conceptualising customer-perceived value. Marketing Review, v. 12, n. 3, p. 253-274, 2012. DOI: https://doi.org/10.1362/146934712X13420906885395. 
CHAVES, P. G., GOSLING, M., MEDEIROS, S. A. Engajamento e ações de marketing de relacionamento no futebol: Um estudo com torcedores do Cruzeiro Esporte Clube. Revista das Faculdades Integradas Viana Júnior, v. 5, n. 1, p. 201-232, 2014.

DAHIRE, S., et al. Bayesian Network inference for probabilistic strength estimation of aging pipeline systems. International Journal of Pressure Vessels and Piping, v. 162, p. 30-39, 2018. DOI: https://doi.org/10.1016/j.ijpvp.2018.01.004.

DICKLER, L. Book review: Strategic Sport Marketing, D. Shilbury, H. Westerbeek, S. Quick, D. Funk, A. Karg, 4th edition, Allen \& Unwin, Crows Nest, New South Wales (2014). Sport Management Review, v.18, n. 4, p. 627-628, 2015. DOI: 10.1016/j.smr.2014.09.004

FAGUNDES, A. F. A. et al. A publicação acadêmica de marketing esportivo no Brasil. Revista Brasileira de Marketing, v. 11, n. 2, p. 94-119, 2012. DOI: 10.5585/remark.v11i2.2327.

FERREIRA, J. C., PATINO, C. M. O que realmente significa o valor-p? Jornal Brasileiro de Pneumologia, v. 41, n. 5, p. 485, 2015. DOI: http://dx.doi.org/10.1590/S1806-37132015000000215.

FIGUEIREDO, G. H., SANTOS, V., CUNHA, P. R. Práticas de Evidenciação em Entidades Desportivas: Um Estudo nos Clubes de Futebol brasileiro. Enfoque: Reflexão Contábil, v. 36, n. 1, p. 1-21, 2017. DOI: http://dx.doi.org/10.4025/enfoque.v36i1.28467.

FLEURY, F. A. et al. Efeito das Vitórias e Derrotas na Atitude do Torcedor de Futebol: um Estudo Envolvendo Garoto-Propaganda, Envolvimento e Fanatismo. Brazilian Business Review, v. 13, n. 4, p. 2550, 2016. DOI: http://dx.doi.org/10.15728/bbr.2016.13.4.2.

GASPAR, M. A. et al. Marketing Esportivo : Um Estudo das Ações Praticadas por Grandes Clubes de Futebol do Brasil. PODIUM Sport, Leisure and Tourism Review, v. 3, n. 1, p. 12-28, 2014. DOI: 10.5585/podium.v3i1.67.

GASPARETTO, T. M. O Futebol Como Negócio: uma comparação financeira com outros segmentos. Revista Brasileira de Ciência do Esporte, v. 35, n. 4, p. 825-845, 2013. DOI: http:/ /dx.doi.org/10.1590/S010132892013000400003.

HAIR, J. F., et al. C. Análise multivariada de dados. 5. ed. Porto Alegre: Bookman, 2005.

HINTERHUBER, A. Towards value-based pricing-An integrative framework for decision making. Industrial Marketing Management, v. 33, n. 8, p. 765-778, 2004. DOI: 10.1016/j.indmarman.2003.10.006.

HIRSCHI, C. Introduction: Applications of Social Network Analysis. Procedia - Social and Behavioral Sciences, v. 4, p. 2-3, 2010. DOI:10.1016/j.sbspro.2010.07.477

ITAÚ BBA. Análise Econômico-Financeira dos Clubes Brasileiros de Futebol, 2016.

LOIS, N. C. Estratégias empiricas em patrocinio esportivo à luz. da experiência de organizações esportivas e empresas investidoras. 2013. 342 f. Tese (doutorado) - Universidade Federal de Santa Catarina, Centro Tecnológico, Programa de Pós-graduação em Engenharia de Produção. Florianópolis, 2013.

LOUVIERE, J. J., FLYNN, T. N., CARSON, R. T. Discrete choice experiments are not conjoint analysis. Journal of Choice Modelling, v. 3, n. 3, p. 57-72, 2010. DOI: https://doi.org/10.1016/S1755-5345(13)700149 
MACAGNAN, L. D. G., BETTI, M. Futebol: representações e práticas de escolares do ensino fundamental. Revista Brasileira de Educação Física e Esporte, v. 28, n. 2, p. 315-27, 2014. DOI: http://dx.doi.org/10.1590/1807-55092014000200315.

MALAGRINO, L. S; ROMAN, N. T; MONTEIRO, N. M. Forecasting stock market index daily direction: A Bayesian Network approach. Expert Systems with Applications, v.105, no1, p.11-22, 2018. DOI: 10.1016/j.eswa.2018.03.039.

MARQUES, D. S. P.; COSTA, A. L. Administração de clubes de futebol profissional: proposta de um modelo específico de governança para o setor. Organizações \& Sociedade, v. 23, n. 78, p. 378-405, 2016. DOI: http://dx.doi.org/10.1590/1984-92307823.

MARTINS, F. F. Marketing de relacionamento no futebol: O programa sócio-torcedor do Sport Club Corinthians Paulista. 2016. 106 f. Dissertação (Mestrado em Administração) - Programa de Estudos PósGraduados em Administração, Pontifícia Universidade Católica de São Paulo, São Paulo, 2016.

MÜLLER, O., SIMONS, A., M. WEINMANN. Beyond crowd judgments: Data-driven estimation of market value in association football. European Journal of Operational Research, v. 263, n. 2, p. 611-6241, 2017. DOI: https://doi.org/10.1016/j.ejor.2017.05.005.

NURAENI, S., ARRU, A. P., NOVANI, S. Understanding Consumer Decision-making in Tourism Sector: Conjoint Analysis. Procedia - Social and Behavioral Sciences, p. 312-317, 2015. DOI: https://doi.org/10.1016/j.sbspro.2015.01.315.

POZZI, L. F. A grande jogada: teoria e prática do marketing esportivo. Porto Alegre: Editora Globo, p. 280, 1998.

RAVALD, A.; GRÖNROOS, C. The value concept and relationship marketing. European Journal of Marketing, v. 30, n. 2, p. 19-30, 1996. DOI: https:// doi.org/10.1108/03090569610106626.

ROCHA, T. V.; TOLEDO, G. L.; ALMEIDA, L. F. DE. A Percepção dos Clientes Agrícolas sobre os Programas de Fidelidade: um estudo de caso. Revista Brasileira de Gestão de Negócios, v. 10, n. 28, p. 282294, 2008.

SARDINHA, R; PAES, A; ZAVERUCHA, G. Revising the structure of Bayesian network classifiers in the presence of missing data. Information Sciences, p. 108-124, 2018. DOI: https://doi.org/10.1016/j.ins.2018.02.011.

SCHARF, E. R. et al. A experiência e mais dez: uma estratégia para vencer na Champions League. Gestão \& Regionalidade, v. 32, n. 96, p. 21-34, 2017. DOI: http://dx.doi.org/10.13037/gr.vol32n96.3461.

SEPTIANTO, F., AN, J., CHIEW, T. M., PARAMITA, W., TANUDHARMA, I. The similar versus divergent effects of pride and happiness on the effectiveness of loyalty programs. Journal of Business Research, v. 99, p. 12-22, 2019. https://doi.org/10.1016/J.JBUSRES.2019.02.021

SHETH, J. N.; NEWMAN, B. I.; GROSS, B. L. Why we buy what we buy: A theory of consumption values. Journal of Business Research, v. 22, n. 2, p. 159-170, 1991. DOI: https://doi.org/10.1016/01482963(91)90050-8. 
SOUZA, E. M. DE; BATISTA, P. C. DE S. Antecedentes e Consequentes Estratégicos para o Desempenho de Empresas de E-Business. Brazilian Business Review, v. 14, n. 1, p. 59-86, 2017. DOI: http://dx.doi.org/10.15728/bbr.2017.14.1.4.

VRONTIS, D. et al. Strategic marketing planning for football clubs: a value-based analysis. Journal for Global Business Advancement, v. 7, n. 4, p. 355-374, 2014. DOI: DOI: 10.1504/JGBA.2014.065593.

WEITZL, W., HUTZINGER, C., EINWILLER, S. An empirical study on how webcare mitigates complainants' failure attributions and negative word-of-mouth. Computers in Human Behavior, v. 89, p. 316327, 2018. DOI: https://doi.org/10.1016/j.chb.2018.07.012.

O presente trabalho foi realizado com o apoio da CAPES. 